\title{
Outcomes of transcatheter closure of ductus arteriosus in infants less than 6 months of age: a single-center experience
}

\author{
Gwang-Jun Choi, MD, Jinyoung Song, MD, PhD, Yi-Seul Kim, MD, Heirim Lee, MD, June Huh, MD, PhD, I-Seok Kang, MD \\ Department of Pediatrics, Samsung Medical Center, Sungkyunkwan University School of Medicine, Seoul, Korea
}

Purpose: Transcatheter device closure of patent ductus arteriosus (PDA) is challenging in early infancy. We evaluated PDA closure in infants less than 6 months old.

Methods: We performed a retrospective review of infants less than 6 months of age who underwent attempted transcatheter device closure in our institution since 2004. To compare clinical outcomes between age groups, infants aged 6-12 months in the same study period were reviewed.

Results: A total of 22 patients underwent transcatheter PDA closure during the study period. Patient mean age was $3.3 \pm 1.5$ months, and weight was $5.7 \pm 1.3 \mathrm{~kg}$. The duct diameter at the narrowest point was $3.0 \pm 0.8 \mathrm{~mm}$ as measured by angiography. The most common duct type was $\mathrm{C}$ in the Krichenko classification. Procedural success was achieved in 19 patients (86.3\%). Major complications occurred in 5 patients (22.7\%), including device embolization ( $n=1)$, acquired aortic coarctation $(n=2)$, accessrelated vascular injury requiring surgery $(n=1)$, and acute deterioration requiring intubation during the procedure $(n=1)$. Two patients had minor complications (9.1\%). Twenty-four infants aged $6-12$ months received transcatheter device closure. The procedural success rate was $100 \%$, and there were no major complications. The major complication rate was significantly higher in the group less than 6 months of age $(P=0.045)$. There was a trend toward increased major complication and procedural failure rates in the younger age group $(P<0.01)$.

Conclusion: A relatively higher incidence of major complications was observed in infants less than 6 months of age. The decision regarding treatment modality should be individualized.

Key words: Congenital heart disease, Patent ductus arteriosus, Transcatheter closure

\section{Introduction}

Patent ductus arteriosus (PDA) causes left heart volume overloading and may lead to congestive heart failure, atrial arrhythmia, or pulmonary hypertension. ${ }^{1)}$ Transcatheter device closure of PDA is an established and widely accepted treatment modality in adolescents, children, and older infants. ${ }^{1-5)}$ However, there is limited evidence and thus far few studies exist for early infants. ${ }^{6-11)}$ The Amplatzer duct occluder (ADO) device is the globally most popular device for PDA, and it is approved to use in infants older than 6 months and weighing more than $6 \mathrm{~kg}$, per the manufacturers. To analyze clinical outcomes and safety of transcatheter closure of PDA in early infancy, we performed a retrospective analysis of infants less than 6 months of age in whom transcatheter device closure was attempted. In addition, we present a comparison of the procedural outcomes between patients less than 6 months old and those 6-12 months old who underwent transcatheter closure of PDA in the same study period.
Corresponding author: Jinyoung Song, MD, PhD Department of Pediatrics, Samsung Medical Center, Heart Vascular Stroke Institute, Grown-up Congenital Heart Clinic, Sungkyunkwan University School of Medicine, 81 Irwon-ro, Gangnam-gu, Seoul 06351, Korea

Tel: $+82-2-3410-3539$

Fax: +82-2-3410-0043

E-mail: amyjys@naver.com

https://orcid.org/0000-0002-9660-5949

Received: 18 April, 2018

Revised: 9 July, 2018

Accepted: 31July, 2018

Copyright ( 2018 by The Korean Pediatric Society

This is an open-access article distributed under the terms of the Creative Commons Attribution NonCommercial License (http://creativecommons.org/ licenses/by-nc/4.0/n which permits unrestricted noncommercial use, distribution, and reproduction in any medium, provided the original work is properly cited. 


\section{Materials and methods}

We reviewed medical records of patients who underwent transcatheter closure of PDA at Samsung Medical Center between 2004 and 2017. PDA closure is generally indicated in patients with signs of left ventricular volume overloading. ${ }^{1)}$ Based on literature; we included patients who had clinical symptoms of volume overload, cardiomegaly on cheat radiography and left ventricular dilatation on echocardiography. However, patients with severe pulmonary hypertension due to other reasons than PDA were excluded. ${ }^{1,7,8)}$ Among these patients, those less than 6 months of age at the time of the procedure were enrolled. To compare the success and complication rates between age groups, the procedural outcomes of patients 6-12 months old who underwent transcatheter device closure in the same study period were also collected. All of the procedures were performed by experienced pediatric interventional cardiologists. This study was approved by the Institutional Review Board of Samsung Medical Center (approval number: SMC 201804-040-001).

\section{Procedure}

Informed consent was obtained from the patients' parents before the procedure. Prophylactic antibiotic cefazolin was administered. Most of the procedures were performed under deep sedation, except for patients who were already mechanically ventilated before the procedure. A 4F sheath was placed in the femoral artery and vein. After collecting hemodynamic data, images of the ductus were obtained by angiography with right lateral oblique and lateral views. With the angiographic images, the ductal type and shape were determined according to the Krichenko classification. ${ }^{12)}$ Then, the type and size of the device were chosen considering the ductal anatomy. A delivery catheter was passed through the PDA from the femoral vein to the descending aorta over a guide wire. The device was then advanced into the delivery catheter. For the device, ADO I, Amplatzer vascular plug (AVP) II, and Cocoon PDA were used. After deployment of the device, an aortogram was obtained to evaluate residual shunts and device position. The fluoroscopy time was recorded.

\section{Evaluation after implantation}

Transthoracic echocardiography was conducted within 48 hours after the procedure. Then, routine follow-ups were done at one and six months after discharge. All of the complications related to the procedures were recorded. Cardiac arrest or death, hemodynamic instability, deterioration of respiration requiring mechanical ventilation during the procedure, embolization of the device, acquired coarctation requiring surgery, and vascular complications requiring surgery were classified as major complications. Mild left pulmonary artery (LPA) stenosis, blood transfusion, and transient local vascular complications such as transient loss of pulse or hematoma were classified as minor complications. Successful device deployment and absence of significant residual flow at the latest follow-up were counted as procedural success.

\section{Statistics}

All analyses were performed using SPSS version 23 for Windows. Measured data were expressed as mean \pm standard deviation or median. Procedural outcomes for each age group were compared using a chi-square test or Fisher exact test. Cochran-Armitage test was used for trend analysis. A $P$ value of $<0.05$ is defined as statistically significant.

\section{Results}

A total of 22 patients less than 6 months of age underwent transcatheter PDA closure during the study period. Eleven patients were girls (50\%). The patients' mean age was $3.3 \pm 1.5$ months (range, 0.4-5.9 months), and the mean body weight was $5.7 \pm 1.3 \mathrm{~kg}$ (range, $3.6-8.3 \mathrm{~kg}$ ). All patients had clinically significant symptoms of PDA including weight stagnation or difficulty breathing. Twelve patients $(55 \%)$ had associated cardiac anomalies: atrial septal defect $(n=10)$, ventricular septal defect $(n=1)$, pulmonary stenosis $(n=1)$, aortic stenosis $(n=1)$, or aortic arch hypoplasia and right coronary artery fistula $(n=1)$. The patient characteristics and procedural data are given in Table 1.

The mean duct diameter at the narrowest point measured by echocardiography and angiography was 3.5 $\pm 0.7 \mathrm{~mm}$ (range, 2.2-5.0 $\mathrm{mm}$ ) and 3.0 $\pm 0.8 \mathrm{~mm}$ (range, 1.5-4.5 mm), respectively. Ductal types were classified based on the Krichenko classification except for three patients whose angiogram images were not available for review. The most common type was $\mathrm{C}(58 \%, \mathrm{n}=11)$, followed by type $\mathrm{A}(32 \%, \mathrm{n}=6)$ and type $\mathrm{B}(10 \%, \mathrm{n}=2)$.

Out of 22 patients, transcatheter closure was successfully performed in 19 (86.3\%). The median follow-up duration was 7.2 months (range, 0.3-50.9 months). An immediate aortogram after deployment of the device was routinely done, and 58\% (11 of 19) of the cases were completely closed. Echocardiography before discharge revealed that 63\% (12 of 19) of patients had a small amount of leakage. However, complete occlusion was confirmed in all 15 cases in which follow-up echocardiography data after discharge were available. The latest data were not available for the last 4 cases because they were sent to regional hospitals for follow-up.

The devices used in successful procedures were ADO I (16 patients, 84\%); Cocoon PDA (1 patient, 5\%); and AVP II (2 patients, 11\%).

Among 3 unsuccessful cases, the first patient was 1 month old, weighed $4.3 \mathrm{~kg}$, and had pulmonary hypertension. The ductal type was A, and the size was $2 \mathrm{~mm}$ at the narrowest point. A 5/4 mm ADO I was successfully implanted initially, but the device dislodged to the descending aorta after the procedure (Fig. 1). 
Table 1. Patient characteristics and procedural data

\begin{tabular}{|c|c|c|c|c|c|c|c|c|c|c|c|c|c|}
\hline $\begin{array}{l}\text { Patient } \\
\text { number }\end{array}$ & $\begin{array}{l}\text { Age } \\
\text { (mo) }\end{array}$ & $\begin{array}{l}\text { Weight } \\
(\mathrm{kg})\end{array}$ & $\begin{array}{l}\text { PDA size by } \\
\text { angiography } \\
\text { (mm) }\end{array}$ & $\begin{array}{c}\text { PDA size by } \\
\text { echocardiography } \\
(\mathrm{mm})\end{array}$ & $\begin{array}{l}\text { PDA } \\
\text { type }\end{array}$ & Device & $\begin{array}{l}\text { Device } \\
\text { size } \\
(\mathrm{mm})\end{array}$ & $\begin{array}{l}\text { Qp/ } \\
\text { Qs }\end{array}$ & $\begin{array}{l}\text { PA systolic } \\
\text { pressure } \\
(\mathrm{mmHg})\end{array}$ & $\begin{array}{l}\text { PT } \\
\text { (min) }\end{array}$ & $\begin{array}{c}\mathrm{FT} \\
(\mathrm{min})\end{array}$ & $\begin{array}{c}\text { Major } \\
\text { complications }\end{array}$ & $\begin{array}{c}\text { Procedural } \\
\text { success }\end{array}$ \\
\hline 1 & 0.4 & 4.1 & 1.5 & 4.0 & A & ADO I & $5 / 4$ & 1.3 & 27 & 109 & 19 & No & Yes \\
\hline 2 & 1.3 & 4.3 & 2.0 & 2.2 & B & ADO I & $6 / 4$ & 1.1 & 70 & 66 & 12.5 & $\mathrm{COA}$ & No \\
\hline 3 & 1.3 & 4.3 & 2.0 & 3.2 & A & ADO I & $5 / 4$ & $N R$ & 48 & 53 & $N R$ & Embolization & No \\
\hline 4 & 2.0 & 4.0 & 3.4 & 3.8 & C & AVP \| & 10 & NR & 52 & 71 & 3.0 & No & Yes \\
\hline 5 & 2.0 & 3.6 & 3.4 & 3.4 & B & AVP ॥ & 6 & $\mathrm{NR}$ & 47 & 45 & 12.8 & No & Yes \\
\hline 6 & 2.2 & 4.2 & 4.1 & 4.0 & C & ADO I & $8 / 6$ & 2.8 & 66 & 47 & 10.0 & No & Yes \\
\hline 7 & 2.4 & 5.7 & 3.0 & 3.3 & C & ADO I & $8 / 6$ & NR & 51 & 39 & $N R$ & No & Yes \\
\hline 8 & 2.7 & 3.6 & 3.9 & 3.3 & C & ADO I & $5 / 4$ & 4.9 & 59 & 65 & 12.8 & Access related & Yes \\
\hline 9 & 2.8 & 6.4 & 4 & 4.6 & C & ADO I & $8 / 6$ & 1 & 76 & 39 & 7.0 & No & Yes \\
\hline 10 & 3.0 & 6.0 & 3.3 & 3.3 & C & ADO I & $6 / 4$ & 1.8 & 66 & 46 & 7.0 & No & Yes \\
\hline 11 & 3.0 & 6.7 & 3.0 & 4.0 & $N R$ & Coccoon PDA & $8 / 6$ & NR & 63 & 48 & 9.2 & No & Yes \\
\hline 12 & 3.2 & 5.2 & 2.5 & 2.3 & C & AVP ॥ & 6 & $\mathrm{NR}$ & 83 & NR & 19.0 & $\mathrm{CoA}$ & No \\
\hline 13 & 3.4 & 8.0 & 3.1 & 3.5 & $N R$ & ADO I & $6 / 4$ & 1.8 & 26 & NR & $N R$ & No & Yes \\
\hline 14 & 3.6 & 5.6 & 2.6 & 4.2 & A & ADO I & $5 / 4$ & 3.8 & 81 & 38 & 10.3 & No & Yes \\
\hline 15 & 4.1 & 5.8 & 3.3 & 3.1 & A & ADO I & $8 / 6$ & 3.1 & 68 & 66 & 9.6 & No & Yes \\
\hline 16 & 4.4 & 5.6 & 2.6 & 3.3 & C & ADO I & $8 / 6$ & 2.3 & 64 & 143 & 8.5 & No & Yes \\
\hline 17 & 4.8 & 7.0 & 2.5 & 2.9 & C & ADO I & $5 / 4$ & 4.5 & 30 & 63 & 4.5 & No & Yes \\
\hline 18 & 5.0 & 8.3 & 3.7 & 5.0 & NR & ADO I & $8 / 6$ & NR & NR & 56 & 4.0 & No & Yes \\
\hline 19 & 5.1 & 6.6 & 2.3 & 3.0 & C & ADO I & $5 / 4$ & 2.8 & NR & 48 & 4.5 & No & Yes \\
\hline 20 & 5.5 & 6.8 & 2.9 & 3.6 & A & ADO I & $6 / 4$ & 1.8 & 52 & 99 & 12.7 & No & Yes \\
\hline 21 & 5.5 & 6.9 & 4.5 & 4.5 & C & ADO I & $8 / 6$ & 1.5 & 73 & $\mathrm{NR}$ & 18.7 & PHT crisis & Yes \\
\hline 22 & 5.9 & 6.2 & 4.0 & 4.5 & A & ADO I & $8 / 6$ & 3.0 & 50 & 84 & 8.3 & No & Yes \\
\hline
\end{tabular}

PDA, patent ductus arteriosus; Qp/Qs, pulmonary to systemic blood flow ratio; PA, pulmonary artery; PT, procedure time; FT, fluoroscopy time; AD0, Amplatzer duct occluder; CoA, coarctation of aorta; NR, not recorded; AVP, amplatzer vascular plug; PHT, pulmonary hypertensive.

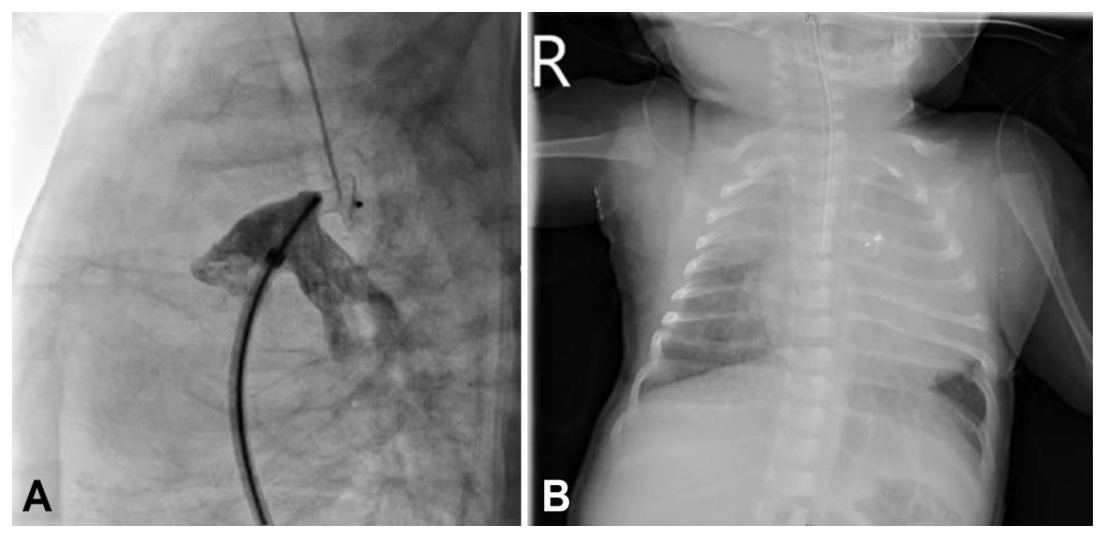

Fig. 1. (A) Angiogram of a 1-month-old, 4.3-kg infant in lateral view showing closure of a 2-mm ductus using a 5/4-mm Amplatzer device occluder device without residual shunt. (B) Postprocedural chest $\mathrm{X}$-ray revealed device embolization that required surgery.

Therefore, emergent surgical removal of the device and closure of the ductus were needed. The second patient was 1 month old and weighed $4.0 \mathrm{~kg}$. The ductal type was B, and the size was $2 \mathrm{~mm}$. A $6 / 4 \mathrm{~mm}$ ADO I was implanted (Fig. 2). Device deployment led to acquired coarctation of the aorta. Surgical device removal and ductal ligation were planned. The third patient had Down syndrome and severe pulmonary hypertension with arch hypoplasia; she was three months old and weighed $5.2 \mathrm{~kg}$. The ductal type was $\mathrm{C}$, and the size was $2.5 \mathrm{~mm}$. An implanted 6-mm AVP II device resulted in a significant pressure difference between the ascending and descending aortas (Fig. 3). Therefore, the device was retrieved immediately by the transcatheter approach. 
Major complications occurred in 5 patients (22.7\%). There was no cardiac arrest or mortality related to the procedure. There was one case of device embolization after the procedure, requiring surgical removal as described above. Out of five patients, device deployment caused significant aortic coarctation in 2 patients, and the device was removed as described above. An access-related major complication occurred in one patient; initial delivery of a 5/4 mm $\mathrm{ADO}$ was attempted with $6 \mathrm{~F}$ and $7 \mathrm{~F}$ sheaths, but advancement

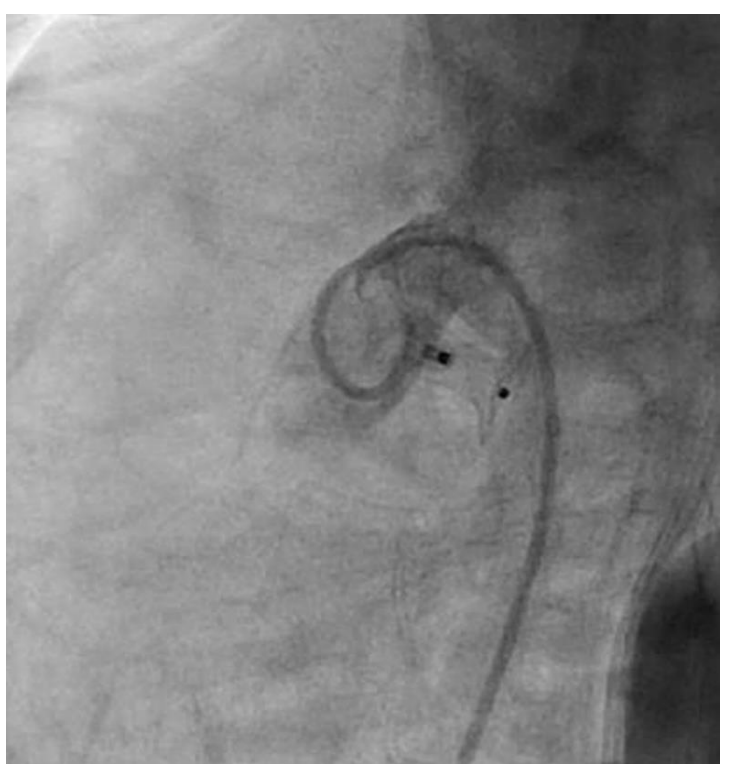

Fig. 2. Angiogram of a 1-month-old, 4.3-kg infant in lateral view showing closure of a 2-mm ductus using a 6/4-mm Amplatzer device occluder device. The retention disc produced aortic coarctation.

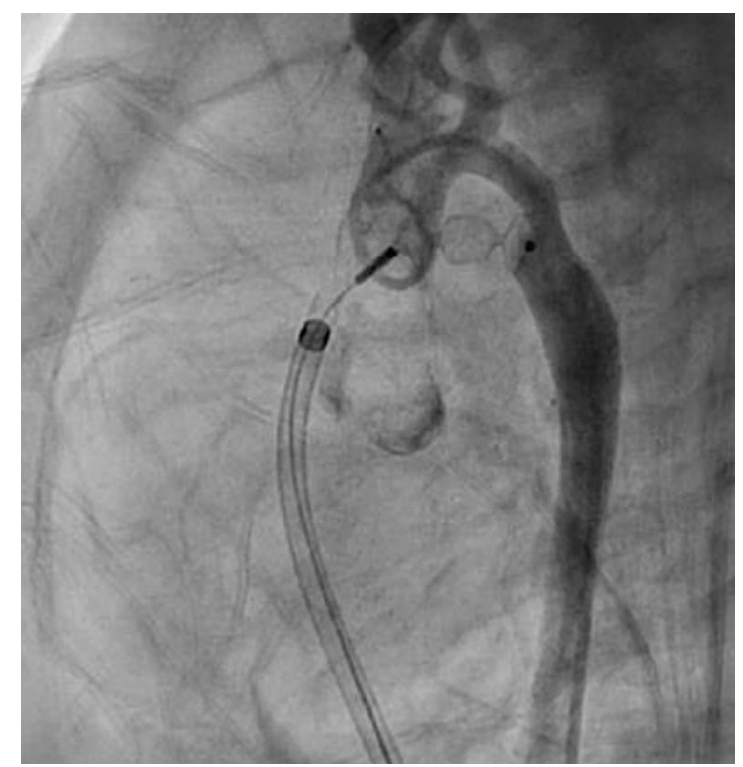

Fig. 3. Angiogram of a 3-month-old, 5.2-kg infant with arch hypoplasia, in lateral view showing a, Amplatzer vascular plug II 6-mm device used to close a $2.5-\mathrm{mm}$ ductus. The device produced a significant pressure gradient between the ascending and descending aortas. was not possible. Eventually, with an 8F short sheath, deployment of the device was successful. However, damaged vascular tissue was identified with the removed vascular sheath, and a common iliac vein injury was detected on angiogram. Therefore, the patient underwent emergent allograft surgery. A pulmonary hypertensive crisis occurred in the last patient during the procedure. Emergent intubation and monitoring in an intensive care unit after the procedure were needed.

Two patients had minor complications (9.1\%). For 1 patient, loss of pulse was identified after the procedure and was completely recovered with intravenous heparinization. He also had mild LPA stenosis after device deployment. Mild LPA stenosis was identified in 2 patients. Flow velocity measured by echocardiography was not significant (below $2 \mathrm{~m} / \mathrm{sec}$ ) in both cases. No patient required a blood transfusion due to blood loss during the procedure.

We compared the success and complication rates of the less than 6 months age group with 24 infants aged 6-12 months who received transcatheter device closure in the same study period at our institute. The procedural success rate of the 6-12 months group was higher (100\%), but the difference between the age groups was not statistically significant $(P=0.101)$. In the less than 6 months age group, the major complication rate was $22.7 \%$. In contrast, there was no major complication in the 6-12 months group; this was statistically significant $(P=0.045)$.

As, infant's bodyweight is usually doubled in first 3 months after birth. We further divided under 6 months age group to under 3 months and 3-6 months age groups. Between 3 age groups, only, major complication rate between under 3 months group and 6-12 months group was significantly different $(P=0.015)$. But with trend analysis using linear-by-linear association test, there was a trend of increased major complication and procedural failure rates with younger age group $(P<0.01)$ (Table 2$)$.

\section{Discussion}

To our knowledge, successful transcatheter closure of ductus arteriosus has been reported even in early infancy at less than six months of age, but the major complication rate was significantly higher compared to the older age infants group.

There have been a few studies that evaluated the feasibility of

Table 2. Comparison of procedural outcomes in 3 age groups

\begin{tabular}{lcccc}
\hline \multirow{2}{*}{ Outcome } & \multicolumn{3}{c}{ Age group (mo) } & \multirow{2}{*}{ Pvalue } \\
\cline { 2 - 4 } & $<3(\mathrm{n}=9)$ & $3-6(\mathrm{n}=13)$ & $6-12(\mathrm{n}=24)$ & \\
\hline Procedural success & $7(78.8)$ & $12(92.3)$ & $24(100)$ & $<0.01$ \\
Major complication & $3(33.3)$ & $2(15.4)$ & $0(0)$ & $<0.01$ \\
Minor complication & $1(11.1)$ & $1(7.6)$ & $3(12.5)$ & 0.825 \\
\hline
\end{tabular}

Values are presented as number (\%). 
transcatheter closure of PDA in small infants less than $6 \mathrm{~kg}$, with procedural success rates ranging from 89.7\%-94.3\% ${ }^{6-11)}$ Although the patient population was heterogeneous, different inclusion criteria and different definitions of procedural success and major complications between studies make comparison difficult. In our study, the procedural success rate of infants less than 6 months old was $86.3 \%$, which is comparable with previously reported studies. The slightly lower success rate in our study may have been affected by the relatively small sample size and minimal experience, considering three failed procedures occurred in the first half of all of the attempts.

Backes et al..$^{5}$ conducted a meta-analysis of transcatheter closure of PDA during infants aged less than 1 year. The study reported a success rate of $92.2 \%$ and an overall clinically significant complication rate of $10.1 \%$. It is noteworthy that, in the subgroup analysis, the clinically significant complication rate was 2 to 3 times greater in studies with infants weighing less than $6 \mathrm{~kg}$. A United Kingdom and Ireland multicenter study reported a successful device implantation rate of 92\% in small infants less than $6 \mathrm{~kg}$. ${ }^{6}$ However, a major complication rate of $10 \%$, device embolization rate of 5\%, and vascular access-related complication rate of 6\% led authors to conclude that careful consideration is needed before deciding upon treatment modality. Similarly, in our study, the major complication rate was significantly higher among infants less than 6 months of age. Backes et al. ${ }^{11)}$ reported that younger age less than 30 days was a risk factor of major adverse event and composite failure. In our study, only 1 patient was younger than 30 days and the procedure was successfully done without complication.

As small infants have relatively smaller-sized vessels, concerns about the increased risk of device protrusion into the aorta or pulmonary artery and local vascular injury are major drawbacks in expanding the application of the transcatheter approach to small infants. ${ }^{1)}$ Other than the small size of the aortic isthmus, the acute angle between PDA and the aorta and the absence of aortic ampulla in PDA types B and C were hypothesized as potential factors influencing device protrusion. ${ }^{8}$ There were 2 cases of mild LPA stenosis and 2 cases of significant aortic coarctation in our study. In the aortic coarctation cases, the PDA types were B and C, respectively. Furthermore, 1 patient had mild arch hypoplasia. Therefore, an absence of aortic end ampulla and underlying arch hypoplasia might increase the risk of device protrusion in our study. In the aortic coarctation cases, a 6/4 mm ADO I and 6-mm AVP II were used. A miniaturized device such as ADO II additional size might be helpful in these cases but was not available at the time. ${ }^{13)}$

Device embolization is another major concern in PDA device closure in small infants. Underestimation of PDA size, unfavorable ductal anatomy, and a suboptimal device position can be causes of embolization. ${ }^{6}$ Device embolization rates in small infants less than $6 \mathrm{~kg}$ were reported to be $2.4 \%-5 \%{ }^{6,11)}$ Similarly, there was 1 case (4.5\%) of device embolization in our study. Underestimation of ductal size due to spasm was thought to be the cause of embolization in our case.

To prevent major complications, case by case approach is needed considering patient's condition, ductal anatomy, operator's experience, appropriate device selection and availability of surgical back-up. With our experience, large vascular sheath over 7F should be used with caution in early infants. And, procedures in patient with unfavorable vascular anatomy like aortic coarctation should be avoided. So, thorough evaluation of patient's anatomy with echocardiography and computed tomography is needed in advance. However, we are expecting advances in occlude device and delivery system will help overcome these hurdles in the future.

There are several limitations in this study. Based on the manufacturer's recommendation, we set an arbitrary cutoff of 6 months of age. Due to the retrospective nature of this study, the follow-up duration and interval varied between patients, and data was incomplete in some cases. Although the procedural success rates were lower in the under 6 months age group, the difference was not statistically significant. This may be due to the small sample size.

In conclusion, Transcatheter closure of PDA is a successful and effective treatment option for a majority of early infants. However, a relatively higher incidence of major complications was observed in infants less than 6 months of age. There was a trend of increased major complication and procedural failure rates with younger age group. Considering ductal anatomy, device availability, patients' clinical situations, and operators' experience, the decision of treatment modality should be individualized, and it should be done with precaution and surgical back-up.

\section{Conflicts of interest}

No potential conflict of interest relevant to this article was reported.

\section{References}

1. Baruteau AE, Hascoët S, Baruteau J, Boudjemline Y, Lambert V, Angel $\mathrm{CY}$, et al. Transcatheter closure of patent ductus arteriosus: past, present and future. Arch Cardiovasc Dis 2014;107:122-32.

2. Behjati-Ardakani M, Rafiei M, Behjati-Ardakani MA, Vafaeenasab M, Sarebanhassanabadi M. Long-term results of transcatheter closure of patent ductus arteriosus in adolescents and adults with amplatzer duct occluder. N Am J Med Sci 2015;7:208-11.

3. Delaney JW, Fletcher SE. Patent ductus arteriosus closure using the Amplatzer ${ }^{\circledR}$ vascular plug II for all anatomic variants. Catheter Cardiovasc Interv 2013;81:820-4.

4. Sinha SK, Razi M, Pandey RN, Kumar P, Krishna V, Jha MJ, et al. Prospective evaluation of the feasibility, safety, and efficacy of Cocoon Duct Occluder for transcatheter closure of large patent ductus arteriosus: a single-center study with short- and medium-term follow-up results. Anatol J Cardiol 2017;18:321-7.

5. Backes CH, Rivera BK, Bridge JA, Armstrong AK, Boe BA, Berman 
DP, et al. Percutaneous patent ductus arteriosus (PDA) closure during infancy: a meta-analysis. Pediatrics 2017 Feb;139(2). pii: e20162927. https://doi.org/10.1542/peds.2016-2927.

6. Kang SL, Jivanji S, Mehta C, Tometzki AJ, Derrick G, Yates R, et al. Outcome after transcatheter occlusion of patent ductus arteriosus in infants less than $6 \mathrm{~kg}$ : A national study from United Kingdom and Ireland. Catheter Cardiovasc Interv 2017;90:1135-44.

7. Dimas VV, Takao C, Ing FF, Mattamal R, Nugent AW, Grifka RG, et al. Outcomes of transcatheter occlusion of patent ductus arteriosus in infants weighing $\leq 6 \mathrm{~kg}$. JACC Cardiovasc Interv 2010;3:1295-9.

8. Abadir S, Boudjemline Y, Rey C, Petit J, Sassolas F, Acar P, et al. Significant persistent ductus arteriosus in infants less or equal to $6 \mathrm{~kg}$ : percutaneous closure or surgery? Arch Cardiovasc Dis 2009;102:53340.

9. Baspinar O, Sahin DA, Sulu A, Irdem A, Gokaslan G, Sivasli E, et al. Transcatheter closure of patent ductus arteriosus in under $6 \mathrm{~kg}$ and premature infants. J Interv Cardiol 2015;28:180-9.

10. Sivakumar K, Francis E, Krishnan P. Safety and feasibility of transcatheter closure of large patent ductus arteriosus measuring $>0 \mathrm{r}=4 \mathrm{~mm}$ in patients weighing $<$ or=6 kg. J Interv Cardiol 2008;21:196-203.

11. Backes CH, Kennedy KF, Locke M, Cua CL, Ball MK, Fick TA, et al. Transcatheter occlusion of the patent ductus arteriosus in 747 infants $<6 \mathrm{~kg}$ : insights from the NCDR IMPACT Registry. JACC Cardiovasc Interv 2017;10:1729-37.

12. Krichenko A, Benson LN, Burrows P, Möes CA, McLaughlin P, Freedom RM. Angiographic classification of the isolated, persistently patent ductus arteriosus and implications for percutaneous catheter occlusion. Am J Cardiol 1989;63:877-80.

13. Baspinar O, Irdem A, Sivasli E, Sahin DA, Kilinc M. Comparison of the efficacy of different-sized Amplatzer duct occluders (I, II, and II AS) in children weighing less than $10 \mathrm{~kg}$. Pediatr Cardiol 2013;34:88-94. 